\title{
Aspects of design of experiments on machining technology by forming the internal threads
}

\author{
Sandor Ravai-Nagy ${ }^{1, *}$, Nicolae Medan ${ }^{1}$, and Ferencz Szigeti ${ }^{2}$ \\ ${ }^{1}$ Technical University of Cluj-Napoca, North University Center Baia Mare, Dr. V. Babeş str., 62A, \\ 430083, Baia Mare, Romania \\ ${ }^{2}$ University of Nyíregyháza, Institute of Engineering and Agricultural Sciences, Sóstói út 31/B, 4400, \\ Hungary
}

\begin{abstract}
The purpose of this paper is to present the necessary steps to make a design of experiment with application to study the machining of internal thread by cold deformation with roll-form taps for aluminium alloys. In the first part of the paper is presented an exploratory research. The performed experimental studies indicate influences of processing speed on thread resistance. Through the proposed study, we wish to determine the machining regimes and influence of machining regimes on the precision and resistance of the thread.
\end{abstract}

\section{Introduction}

Inside of processing technologies of inner thread beside the cutting method using taps the cold forming methods are used also.

It is known that the cold formed process of aluminium has an influence on the precision of the workpiece [1].

The cold formed thread is more resistant to mechanical stresses than the thread obtained by cutting $[2,3]$. Other advantages of plastic deformation of threads are: high productivity, high precision, surface quality and durability of tools [4].

Because the cold forming taps manufacturing companies recommend working regimes for aluminium alloys in wide range, process speed $V_{c}=5-30 \mathrm{~m} / \mathrm{min}$, for proper use it is necessary to perform further studies and tests. To optimize the working regime, it is necessary to carry out studies for each material and technological processing system.

To carry out an experimental research, it is recommended to follow a series of steps $[5,6]$ :

1. Recognition of and statement of the problem;

2. Selection of the response variable;

3. Choice of factors (process parameters), levels, and ranges;

4. Choice of experimental design;

5. Performing the experiment;

6. Statistical analysis of the data;

7. Conclusions and recommendations.

\footnotetext{
*Corresponding author: Ravai.Nagy.Sandor@,cunbm.utcluj.ro
} 


\section{Exploratory research}

In a first step, threads have been machined to familiarize with thread cold forming technology [7].

In the experiments, M8 threaded holes are machined using two different types of cold forming taps and a classical cutting tap to compare the manufacturing technologies. The processing speeds have been selected at $50 \%$ and $75 \%$ of the maximum speed recommended by the manufacturers. The processed material is Aluminium alloy 6005. For lubrication and cooling, 5\% emulsion was used. In the experiments was used the specific (normal) emulsion for metal cutting, because in the process of manufacturing on CNC machine tools it is very difficult to make use of a different, special, lubrication liquid for the cold forming taps.

In table 1 are presented the results of exploratory experiments.

Table 1. Centralizing exploratory experimental results.

\begin{tabular}{|c|c|c|}
\hline \multirow{2}{*}{ The used tool } & \multicolumn{2}{|c|}{ Exploratory experiment results } \\
\cline { 2 - 3 } & \multicolumn{2}{|c|}{ Processing speed } \\
\cline { 2 - 3 } $\begin{array}{c}\text { Cold forming tap without } \\
\text { cooling/lubrification channel: Walter }\end{array}$ & Thread was formed & $\begin{array}{c}18.75 \mathrm{~m} / \mathrm{min} \\
(75 \%)\end{array}$ \\
$\begin{array}{c}\text { D2061805-M8 M8-6Hx 86378800 HSS-E } \\
\varnothing 7,4 \text { 17/12 }\end{array}$ & $\begin{array}{c}\text { Thread was NOT } \\
\text { formed. The tap was } \\
\text { covered with material } \\
\text { (fig. 1.a) }\end{array}$ \\
\hline $\begin{array}{c}\text { Cold forming tap with } \\
\text { cooling/lubrification channel: Emuge M8- } \\
\text { 6Hx Inno Form 1-Z-1KZ HSSE TIN-T1 52/1 } \\
\varnothing 7,45\end{array}$ & Thread was formed & $\begin{array}{c}\text { Thread was NOT } \\
\text { formed. The tap was } \\
\text { covered with material } \\
\text { (fig. 1.b.) }\end{array}$ \\
\hline $\begin{array}{c}\text { Taps machine with helical grooves for chip } \\
\text { release, M8 }\end{array}$ & Thread was formed & \begin{tabular}{c} 
Thread was formed \\
\hline
\end{tabular} \\
\hline
\end{tabular}

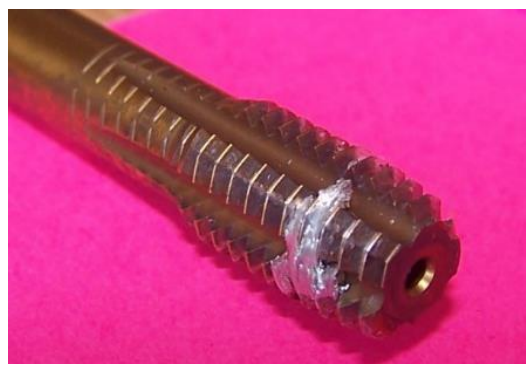

a) Cold forming tap with cooling/lubrification channel

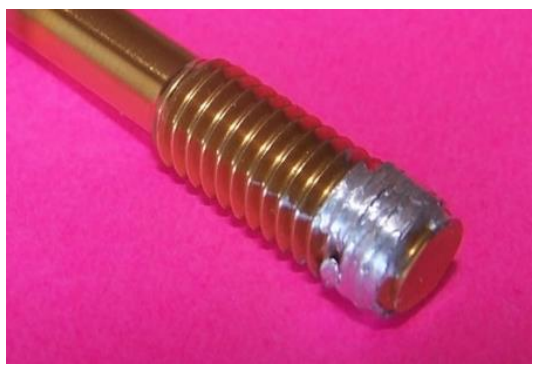

b) Cold forming tap without cooling/lubrification channel

Fig. 1. Cold form taps with grooves covered by material.

The processed threads have been tested to tensile test to establish the shear strength. The obtained results we show in Table 2.

Following the results of the experiments it was ascertain:

- From the point of view of the deformation speed, for value of $18.75 \mathrm{~m} / \mathrm{min}$, the internal thread M8 can not be processed by forming method using cold-forming tap.

- From the point of view of shear strength of the obtained thread, differences were found depending on the used tool. Processing with cold-forming tap without cooling/lubrification 
channel it was ascertain a $14 \%$ increase in shear strength compared whit cutting tap and $7.25 \%$ when processing with Cold-forming tap with cooling/lubrification channel.

Table 2. The measured tensile force.

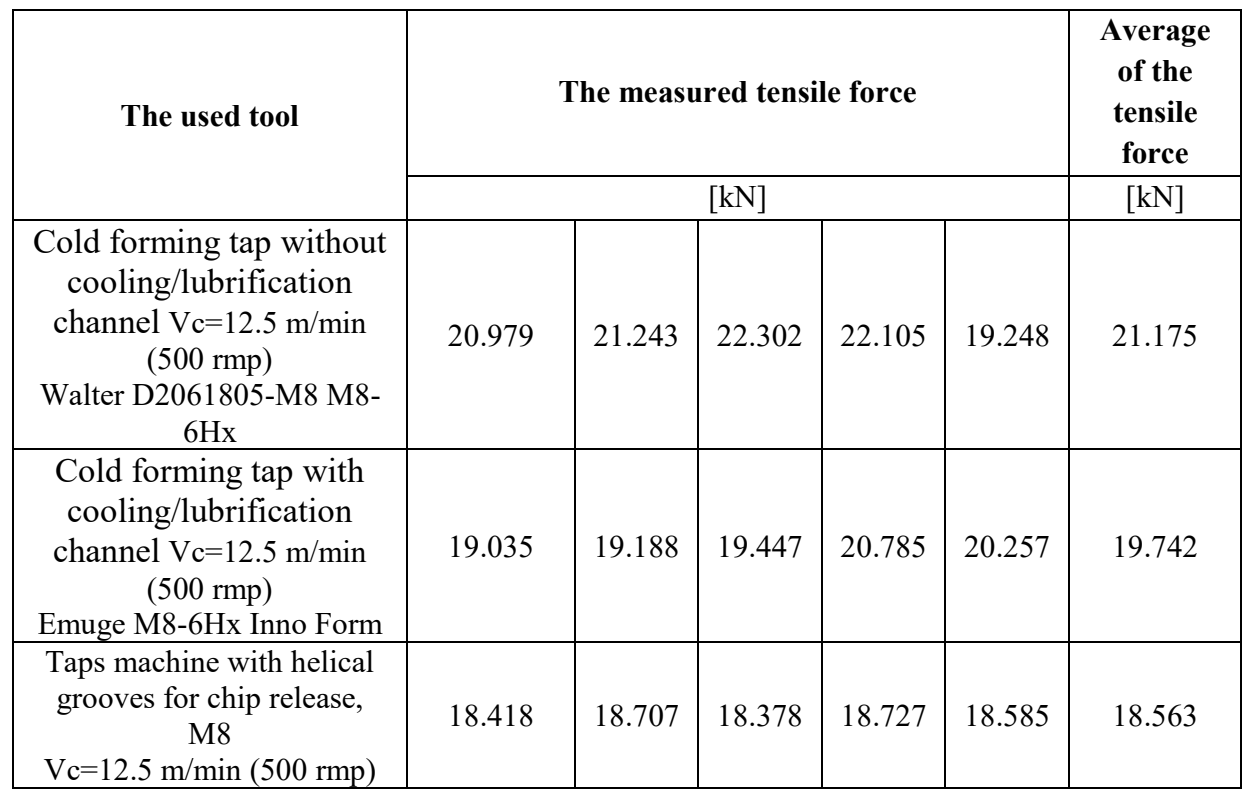

\section{Design of experiments}

Considering the results of the performed experimental exploratory research we propose an experimental research plan to determine the influences of the technological parameters on the thread cold-forming methods.

\subsection{Recognition of and statement of the problem}

After completing field of bibliography and exploratory research, can be formulated the research questions: the influence of processing regimes on the shear resistance of the screw and on thread deformation.

\subsection{Selection of the response variable}

Given the phenomena occurring under thread cold-forming process, response parameters studied are: 1) Thread precision, 2) Thread tensile force.

\subsection{Choice of factors (process parameters), levels, and ranges}

To study the thread cold-forming process the following parameters were identified:

- Process speed. The range of processing speed will have the values: $12.5 \mathrm{~m} / \mathrm{min}, 15 \mathrm{~m} / \mathrm{min}$, $17.5 \mathrm{~m} / \mathrm{min}$ and $18.75 \mathrm{~m} / \mathrm{min}$.

- Tool type used. These are cold-forming tap without cooling/lubrification channel and cold-forming tap with cooling/lubrification channel;

- The size of the processed thread. The range of threads for which there are cold-forming taps is between the values: M1 - M12; 
- Material processed. It is planned to perform experiments on aluminium alloys such as: 5019, 6005, 6082, 7050, 7075 .

- Lubricating fluid: $5 \%$ emulsion, $10 \%$ emulsion, special liquid for cold-forming taps.

In Table 3, the experimental field is presented.

Table 3. Experimental domain.

\begin{tabular}{|c|c|}
\hline Parameter & Values \\
\hline Process speed & $12.5 \mathrm{~m} / \mathrm{min}, 15 \mathrm{~m} / \mathrm{min}, 17.5 \mathrm{~m} / \mathrm{min}$ and $18.75 \mathrm{~m} / \mathrm{min}$ \\
\hline & Cold-forming tap without cooling/lubrification channel \\
B5519Y700. \\
Cool & B521Y700. \\
& M4, M5, M6, M8, M10, M12 \\
\hline Tread dimension & $5019,6005,6082,7050,7075$ \\
\hline Material &
\end{tabular}

\subsection{Choice of experimental design}

In the first stage, we propose an experimental research using the Taguchi method to determine the percentage of influence of the chosen parameters and the interactions between them on the studied phenomenon. Depending on the obtained results in the next step, will be chose the parameters whose influence is significant.

In the second stage, experimental research will be used using the full factorial method.

\subsection{Performing the experiment}

For the processing of the thread will use the technological assembly shown in Figure 2. It consists of:

- Machine tool with CNC control "NTC104N type EML510BR", $\mathrm{n}_{\max }=8000 \mathrm{rmp}, \mathrm{s}_{\max }=30 \mathrm{~m}$ - Clamping device for test piece with force and torque measuring sensor Kistler 9345B or equivalent.

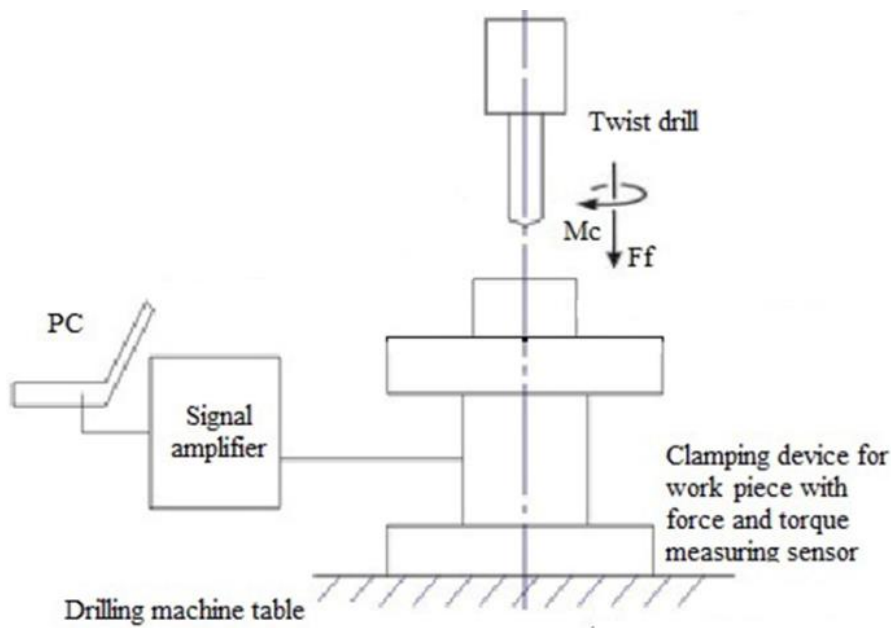

Fig. 2. Stand for manufacturing threads and measuring parameters of the processing regime.

The processed threads will try to tensile using the technological assembling set out in figure 3 , in order to determine the shear resistance of the formed screw of the thread. 


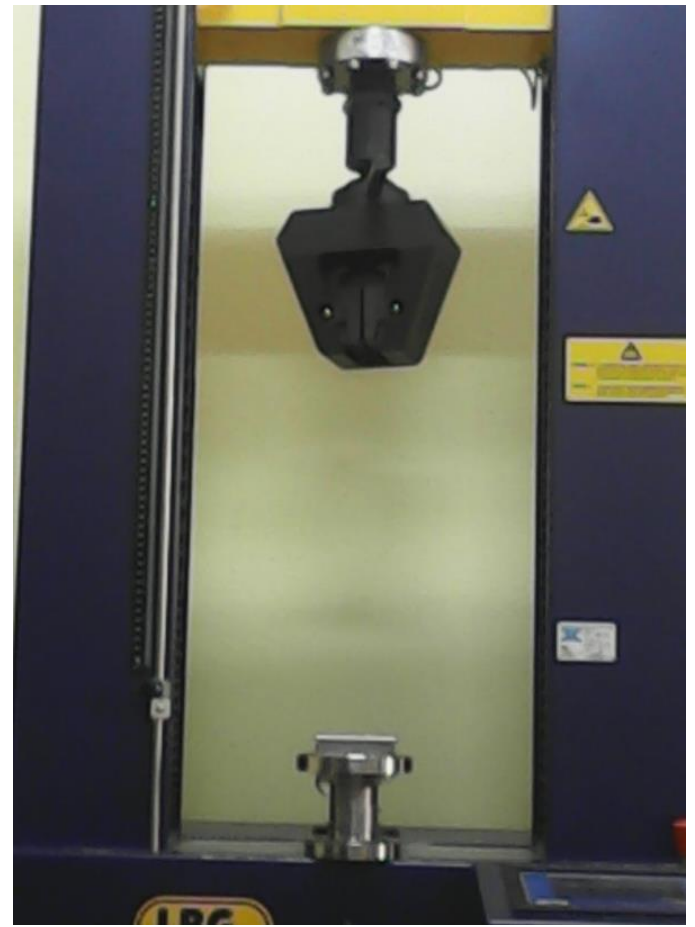

a) Universal testing machine whit fixture device

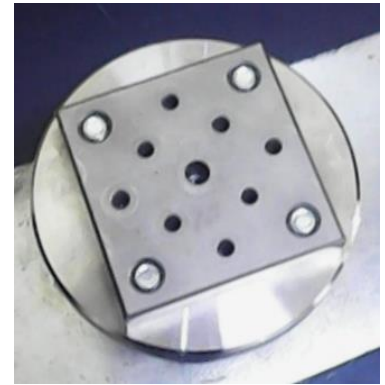

b) The fixture device

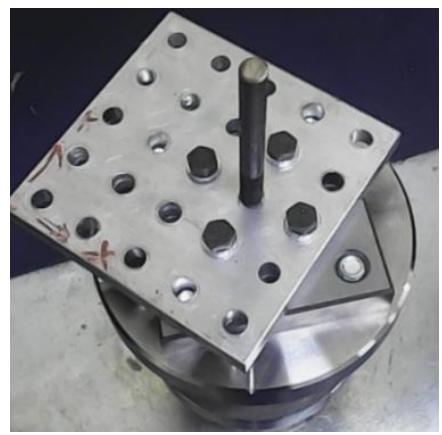

c) The specimen on fixture device and the clamping method

Fig. 3. Technological assembly used in the thread mechanical tensile test.

\subsection{Statistical analysis of the data}

An important role in an experimental research has statistical analysis of the data [8]. Statistical analysis of experimental data obtained certifying that the values are real values of the process studied they are not affected by the system errors or measurement errors.

Statistical analysis of the experimental data consists of:

1) verifying the aleatory character of data. This will be performed using the Young test;

2) To verify the normality of the experimental data distribution will be used Shapiro-Wilk normality test. This test is used for data sets that do not exceed 50 values. In the present case, each data set has a number of seven values;

3) Identifying data affected by aberrant errors can be accomplished by applying the Romanowski test. This test for identifying data affected by aberrant errors having applies for a number of up to 20 data.

After performing statistical analysis of the data can proceed to modelling the experimental data in order to obtain those mathematical models which best describe the process.

\section{Conclusions}

Performing an experimental research requires some steps to obtain conclusive results.

1) By conducting the experimental researches, we aim at obtaining results for the improvement of the cold-forming process of the threads. 
2) In this paper, we present a research methodology in the field of thread cold-forming and the used technological ensemble.

3) The design of experimental research is based on exploratory results already made.

4) In a first step, the exploratory research will be expanded using the Taguchi method to determine the influence of the studied process parameters. This method has the advantage that by performing a small number of experiments it is possible to obtain concrete data about the influence of the process parameters.

5) In the second step, using the data obtained from the application of the Taguchi method, an experimental research will be carried out using the full factorial plan method for the process parameters with major influence.

We want to have data at the end of the experiments with the help of any time, according to the identified parameters we can optimize the thread deforming processing in case of cold-forming taps.

\section{References}

1. S.A. Moldovan, M. Banica, V. Nasui, MATEC Web of Conferences, 112, (2017).

2. Emuge GmbH, Katalog 150. Thread Cutting Technology. Clamping Technology. (2016)

3. Walter AG, Product handbook. Drilling \& Threading (2009)

4. O. Pruteanu, Al. Epureanu, C. Bohosievici, Cs. Gyenge, Tehnologia fabricării mașinilor, EDP, București (1981)

5. D.C. Montgomery, Design and analysis of experiments, 8th edition, Wiley, (2013).

6. M. Țîțu, C. Oprean, A. Boroiu, Cercetarea experimentală aplicată în creşterea calitătii produselor şi serviciilor, Ed. Agir, București (2011)

7. S. Ravai-Nagy, D. I. Vlad, D. C. Tămâian, A. Százvai, Experimental studies on tapered hole manufacturing using roll-form taps. International Multidisciplinary Conference, 12th Edition 24-26 May, Baia Mare - Nyiregyhaza (2017)

8. N. Medan, Hidraulica, 4, 41-47, ISSN 1453 - 7303 (2016) 